\title{
Complications after Transcatheter Closure of Patent Ductus Arteriosus
}

\begin{abstract}
To evaluate the short- and mid-term results and complications ensuing the transcatheter closure of patent ductus arteriosus (PDA). Between October 1999 and December 2005, 117 patients (34 males and 83 females) underwent attempted percutaneous closure of PDA with a minimum diameter of more than $3 \mathrm{~mm}$. Follow-up evaluations were conducted at 1 day and 1, 3, 6, 12 months after the performance of the transcatheter closure. The median age of patients at catheterization was $11 \mathrm{yr}$ (range, 0.6 to $68 \mathrm{yr}$ ), median weight was $30 \mathrm{~kg}$ (range, 6 to $74 \mathrm{~kg}$ ), and the median diameter of PDA was $4 \mathrm{~mm}$ (range, 3 to $8 \mathrm{~mm}$ ). This procedure was conducted successfully in 114 patients $(97.4 \%)$, using different devices. Major complications were detected in 4 patients (3.4\%); significant hemolysis (2), infective endocarditis (1), failed procedure due to embolization (1). Minor complications occurred in 6 patients (5.1\%); mild narrowing of the descending aorta (2) and mild encroachment on the origin of the left pulmonary artery (4). Although the transcatheter closure of PDA may be considered to be effective, several complications, including hemolysis, embolization, infective endocarditis, and the narrowing of adjacent vessels may occur in certain cases.
\end{abstract}

Key Words : Patent Ductus Arteriosus; Catheterization; Complications

\author{
Gi Young Jang, Chang Sung Son, \\ Joo Won Lee, Jae Young Lee*, \\ Soo Jin Kim*
}

Department of Pediatrics, Korea University Hospital Seoul; Department of Pediatrics*, Sejong Hospital,

Bucheon, Korea

Received : 27 April 2006

Accepted : 28 November 2006

Address for correspondence

Gi Young Jang, M.D.

Department of Pediatrics, Korea University Hospital, 516 Gojan 1-dong, Danwon-gu, Ansan 425-707, Korea Tel : +82.31-412-5096, Fax : +82.31-405-8591

E-mail : jgynhg@dreamwiz.com

\section{INTRODUCTION}

The first closure of patent ductus arteriosus (PDA) was reported by Porstmann et al. (1) in 1971. Thereafter, several different devices have been used in the interventional occlusion of a PDA, and have produces varying degrees of success. Gianturco embolization coils and Cook detachable coils (Cook Cardiology, Bloomington, IN, U.S.A.) have proven both safe and effective in the closure of small- to moderate sized PDA (2-4). However, they have not been shown to be effective in the closure of large PDA. For the transcatheter closure of moderate to large PDA, the Amplatzer ductal occluder (ADO) device (AGA Medical Corporation, Golden Valley, Minnesota, U.S.A.) and the Nit-Occlud (Pfm, Cologne, Germany) device have been developed, and have met with relatively favorable outcomes $(5,6)$.

However, some complications have still been reported to occur after the transcatheter closure of $\operatorname{PDA}(7,8)$. In the present report, we described the short- and mid-term results and complications we encountered after the interventional occlusion of a PDA with a minimum diameter of more than $3 \mathrm{~mm}$, using different devices.

\section{MATERIALS AND METHODS}

\section{Patients}

Between October 1999 and December 2005, 117 patients (34 males, 83 females) with PDA, with a minimum diameter of more than $3 \mathrm{~mm}$, underwent transcatheter PDA closure procedures (Fig. 1). Informed consent was obtained from all patients prior to performance of the procedures. The median age of the 117 patients at catheterization was $11 \mathrm{yr}$ (range, 0.6 to $68 \mathrm{yr}$ ), and the median weight was $30 \mathrm{~kg}$ (range, 6 to $74 \mathrm{~kg}$ ). We included patients with PDA, with a minimum diameter of more than $3 \mathrm{~mm}$ as evidenced by an angiogram.

\section{Devices and procedures}

The interventional procedure was conducted under local anesthesia. All patients received prophylactic antibiotic therapy prior to catheterization. After the percutaneous puncture of the femoral vein and artery, all hemodynamic variables were evaluated. The shape and size of the PDA were then assessed via an aortogram, from the right anterior oblique and lateral projections. The ductal shape was classified in accordance with the classifications established by Krichenko et al. (9). On the 
basis of ductal morphology and size, interventional occlusions were conducted with ADO (97 patients), Cook detachable coil (15 patients), Nit-Occlud coil (4 patients), or a buttoned device combined with a Cook detachable coil (1 patient). The ADO device used was 1-2 $\mathrm{mm}$ larger than the narrowest diameter of the PDA, and was implanted via a venous approach. In the usage of the Nit-Occlud coils, we selected coils on the basis of the following criteria; the largest device loop diameter was equal to the aortic ampulla and was $3-4 \mathrm{~mm}$ larger than the narrowest duct diameter, and was deployed via the venous approach. In the multiple detachable coils approach, the first coil used was approximately 2.5 times larger than the narrowest diameter of the PDA, and the second coil used was 1.5 to 2.0 times larger than the narrowest diameter.

\section{Follow-up}

Transthoracic echocardiographic evaluations and chest radiography were conducted on all patients prior to discharge, and at 1, 3, 6, 12 months after the procedure. Follow-up evaluations at 12 months were not perfomed yet in a few patients due to the short-term follow-up period. Special attention was paid to the residual PDA flow and protrusion of the device

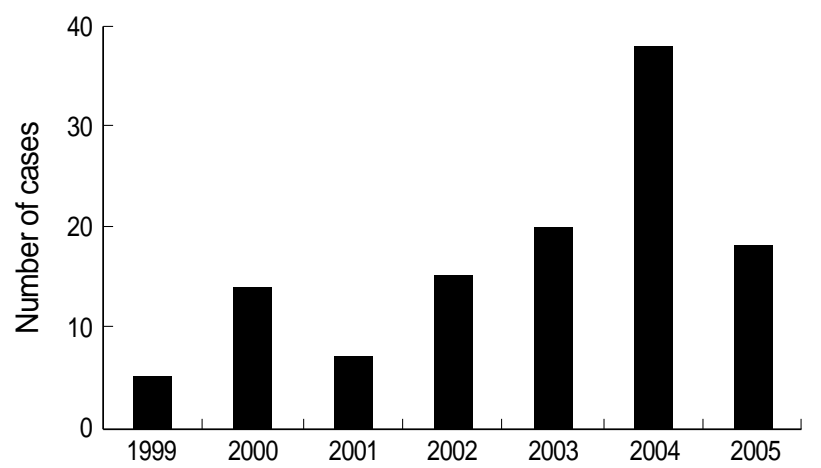

Fig. 1. Distribution of cases by year. into the left pulmonary artery or into the descending aorta.

\section{RESULTS}

The transcatheter closure was conducted successfully in $114(97.4 \%)$ out of 117 patients, using different devices including the ADO, Nit-Occlud coil, and Cook detachable coils. The median fluoroscopy time for PDA closure was 16 minutes (range, 3 to $40 \mathrm{~min}$ ), median pulmonary artery mean pressure was $26 \mathrm{mmHg}$ (range, 13 to $66 \mathrm{mmHg}$ ), and the median Qp/Qs ratio (pulmonary/systemic flow ratio) was 1.9 (range 1.1 to 4.8). According to the classifications established by Krichenko et al., the PDA assumed a conical shape in 95 patients (81.1\%), a tubular shape in 15 patients (12.8\%), and a window-like morphology in 7 patients (5.9\%). The median value of the narrowest PDA diameter, as determined by aortography, was $4 \mathrm{~mm}$ (range 3 to $8 \mathrm{~mm}$ ). The echocardiographic examinations showed that complete PDA occlusion was achieved in $79.5 \%$ of patients at $24 \mathrm{hr}, 89.7 \%$ at 1 month, $96 \% 1 \mathrm{yr}$ after the procedure, and 4 patients $(3.4 \%$ ) were shown to have a small residual shunt at the $1 \mathrm{yr}$ follow-up.

Major complications were noted in 4 patients (3.4\%). Two patients showed significant hemolysis due to residual leakage, infective endocarditis was suspected in one patient, and surgical closure due to embolization was observed in one patient.

Table 1. Procedural complications $(n=117)$

\begin{tabular}{lc}
\hline Major complications & \\
Significant hemolysis & 2 \\
Infective endocarditis & 1 \\
Device embolization requiring surgery & 1 \\
Total events & $4(3.4 \%)$ \\
Minor complications & \\
Mild narrowing of left pulmonary artery & 4 \\
Mild narrowing of descending aorta & 2 \\
Total events & $6(5.1 \%)$ \\
\hline
\end{tabular}

Table 2. Clinical data of patients who developed complications

\begin{tabular}{|c|c|c|c|c|c|c|c|c|c|c|}
\hline No & Age (yr) & Weight (kg) & $\begin{array}{l}\text { PDA size } \\
(\mathrm{mm})\end{array}$ & Type & Qp/Qs & $\begin{array}{l}\text { Device } \\
\text { type }\end{array}$ & Size $(\mathrm{mm})$ & Results & $\begin{array}{l}\text { Complica- } \\
\text { tions }\end{array}$ & $\mathrm{FT}(\min )$ \\
\hline 1 & 2.1 & 11.5 & 3.5 & Co & 1.9 & DC & 6.5 & SS & $\mathrm{H}$ & 18 \\
\hline \multirow[t]{2}{*}{2} & 12 & 26 & 5.2 & Co & 2.1 & $\mathrm{BD}$ & 25 & SS & $\mathrm{H}$ & 30 \\
\hline & & & & & & DC & 6.5 & & & \\
\hline 3 & 1.2 & 9.7 & 3.9 & Co & 2.8 & $\mathrm{DC}$ & 6.5 & SS & $E$ & 19 \\
\hline 4 & 7.7 & 18 & 8 & Co & 3.0 & ADO & $12 / 10$ & C & IE & 25 \\
\hline 5 & 0.6 & 6.9 & 5 & Co & 2.5 & ADO & $10 / 8$ & C & Ao, LPA & 10 \\
\hline 6 & 0.5 & 6 & 3.9 & $\mathrm{~T}$ & 3.0 & ADO & $8 / 6$ & $\mathrm{C}$ & Ao & 12 \\
\hline 7 & 5.1 & 17 & 6.2 & $\mathrm{~T}$ & 2.0 & ADO & $10 / 8$ & TS & LPA & 13 \\
\hline 8 & 8.7 & 24 & 3.3 & T & 1.3 & MDC & $8,6.5$ & TS & LPA & 19 \\
\hline 9 & 1.7 & 10 & 3 & $\mathrm{~T}$ & 1.6 & MDC & $6.5,5$ & $\mathrm{C}$ & LPA & 33 \\
\hline
\end{tabular}

ADO, Amplatzer ductal occluder; Ao, aortic narrowing; BD, buttoned device; C, closure; Co, conical type; DC, Cook detachable coil; E, embolization; FT, fluoroscopy time; H, hemolysis; LPA, narrowing of left pulmonary artery; MDC, multiple detachable coils; Qp/Qs, pulmonary/systemic flow ratio; SS, significant residual shunt; T, tubular type; TS, trace shunt; $5,5 \mathrm{~mm} \times 5$ loops; $6.5,6.5 \mathrm{~mm} \times 5$ loops; $8,8 \mathrm{~mm} \times 5$ loops. 
Minor complications were observed in 6 patients (5.1\%): mild stenosis of the left pulmonary artery via device encroachment was detected in 4 patients, and a mild narrowing of the descending aorta was seen in 2 patients (Table 1,2).

\section{Hemolysis}

Two patients developed hemolysis during the study period. In one patient (No 2 in Table 2), a 12-yr-old male, the ductal size was measured at $5.2 \mathrm{~mm}$, and the $\mathrm{Qp} / \mathrm{Qs}$ ratio was 2.1 . The buttoned device was initially implanted for the closure of the PDA. After device occlusion, the patient exhibited significant residual flow, and thereafter, a second transcatheter closure was conducted using a Cook detachable coil (0.038", $6.5 \mathrm{~mm} \times 5$-loops) to close the residual leak. After the performance of a coil occlusion, however, a significant residual jet was observed. Thereafter, urine discoloration was noticed $12 \mathrm{hr}$ after the procedure, hemoglobin levels fell from 13.8 $\mathrm{g} / \mathrm{dL}$ to $11.5 \mathrm{~g} / \mathrm{dL}$, and the patient's direct bilirubin count was elevated, at $2.1 \mathrm{mg} / \mathrm{dL}$. This patient was sent to the operating room in order to deal with significant hemolysis. After the removal of the device, PDA ligation was conducted. In the other patient (No 1 in Table 2), a 2-yr old male, the PDA size was $3.5 \mathrm{~mm}$ with a systolic pulmonary artery pressure of $26 \mathrm{mmHg}$, and a Cook detachable coil $(0.038$ ", $6.5 \mathrm{~mm} \times$ 4-loops) was initially deployed in an inappropriate position with a small amount of residual flow. However, significant residual shunts were observed on echocardiographic examination after the procedure, and slight migration of the coil in ductus was suspected. With regard to our laboratory findings, the patient's hemoglobin levels fell to $8.5 \mathrm{~g} / \mathrm{dL}$. After blood transfusion, the patient was sent to the catheterization laboratory, where the malpositioned coil was retrieved, and another Cook detachable coil (0.038", $6.5 \mathrm{~mm} \times 5$-loops) was re-deployed. In the post-deployment aortography, only a trivial amount of residual flow was observed. After the second procedure, the patient's general condition and laboratory parameters gradually improved.

\section{Infective endocarditis}

Infective endocarditis was suspected in one case (No 4 in Table 2), a 7-yr-old female with an $8 \mathrm{~mm}$ duct with a systolic pulmonary artery pressure of $57 \mathrm{mmHg}$. Her PDA was closed using a 12/10 mm ADO. Immediate post-deployment angiography revealed trivial residual flow through the device (Fig. 2). At the time of admission, the patient was afebrile, and there were no abnormal laboratory findings. However, 1 day after the procedure, the patient appeared febrile and the fever persisted for 3 days, and then subsided for 4 consecutive days. Thereafter, high-grade fever redeveloped and persisted for approximately 30 days despite the proper usage of adequate antibiotics. Laboratory examination revealed a white blood cell count of $14,900 \mathrm{mg} / \mathrm{dL}$, a hemoglobin concentration of $11.4 \mathrm{~g} / \mathrm{dL}$, and a C-reactive protein concentration of $7.01 \mathrm{mg} /$ dL. Although serial blood cultures were acquired from the patient, we isolated no organisms. Upon echocardiographic examination, no vegetation was present. We were unable to locate the cause of fever, with the exception of the possibility of infective endocarditis via device implantation. Therefore, we decided to operate on this patient for the removal of the device and for PDA ligation. After the ADO had been surgically removed and the PDA ligated, the patient eventually achieved a full recovery.
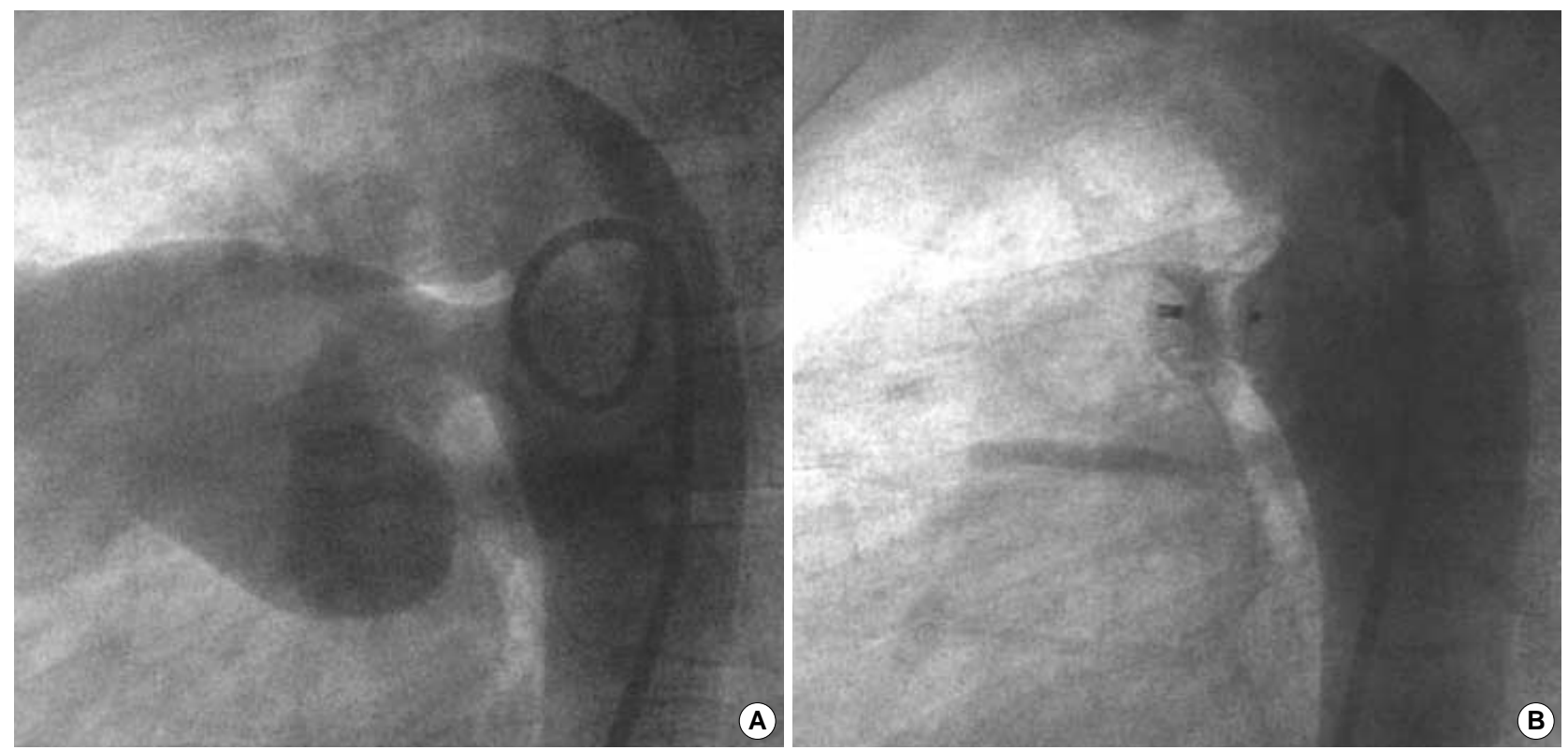

Fig. 2. (A) Lateral aortogram showing a patent ductus arteriosus, $8 \mathrm{~mm}$ in diameter. (B) Lateral aortogram after implantation of a 12/10 mm Amplatzer ductal occluder showing trivial residual flow in the pulmonary artery. 


\section{Device embolization}

This case (No 3 in Table 2) involved a 14-month-old boy with a $3.9 \mathrm{~mm}$ duct, with a systolic pulmonary artery pressure of $28 \mathrm{mmHg}$. A Cook detachable coil (0.038”, $6.5 \mathrm{~mm}$ $\times 5$-loops) was deployed in this case. However, the device embolized to the left pulmonary artery after a few minutes, and the coil was percutaneously retrieved. The patient was then referred for surgical ligation, as no other PDA devices, such as an ADO or Nit-Occlud coil, were available at the time.

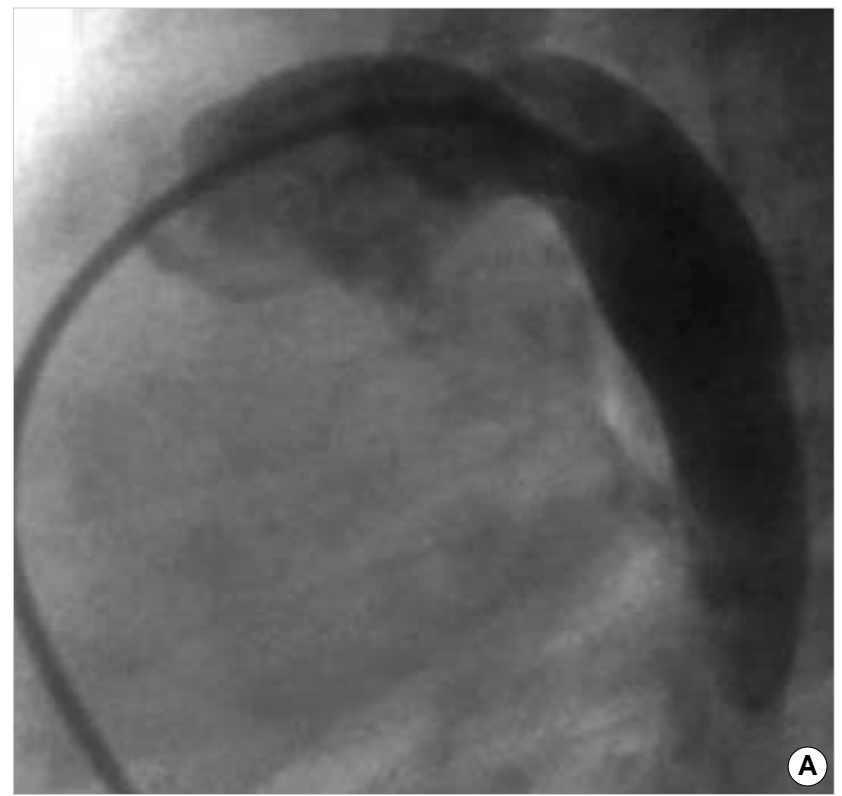

A

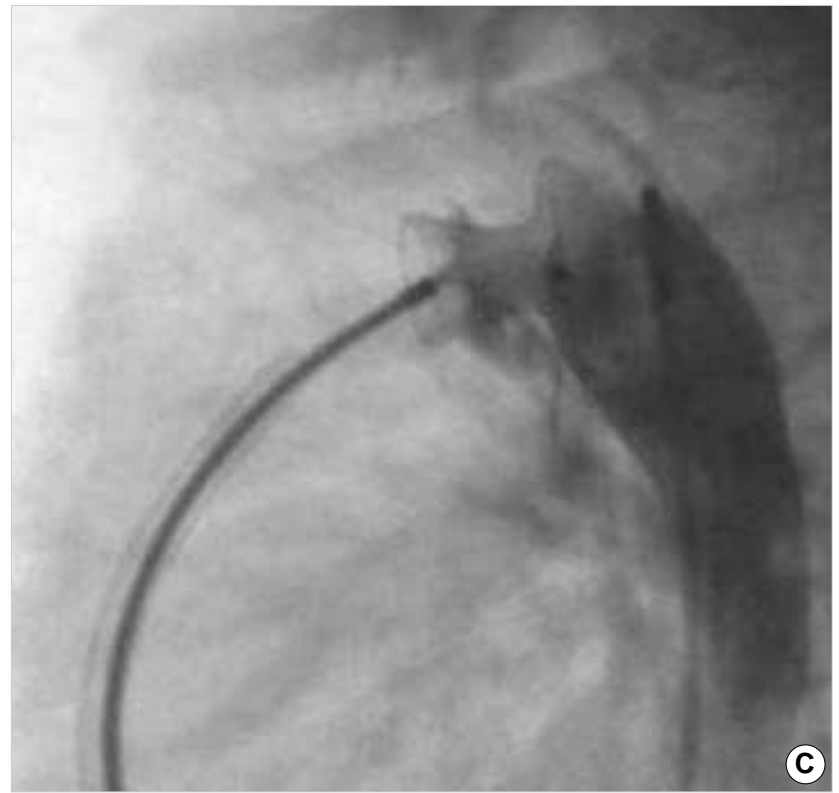

C

\section{Narrowing of descending aorta and pulmonary artery}

In two patients, after the implantation of the $\mathrm{ADO}$, the device was seen to protrude into the descending aorta, resulting in a peak velocity of $2 \mathrm{~m} / \mathrm{sec}$ on Doppler echocardiography in one patient (No 6 in Table 2) and a peak velocity of $2.2 \mathrm{~m} / \mathrm{sec}$ in the other patient (No 5, Fig. 3). The pressure gradient across the aortic isthmus was $2-4 \mathrm{mmHg}$ in the catheterization laboratory in these two patients. One of the patients was 6 month-old, and the other was 7 month-old. Both patients weighed less than $7 \mathrm{~kg}$. In 4 patients (No 5 , 7-9 in Table 2), after the procedure, device encroachment
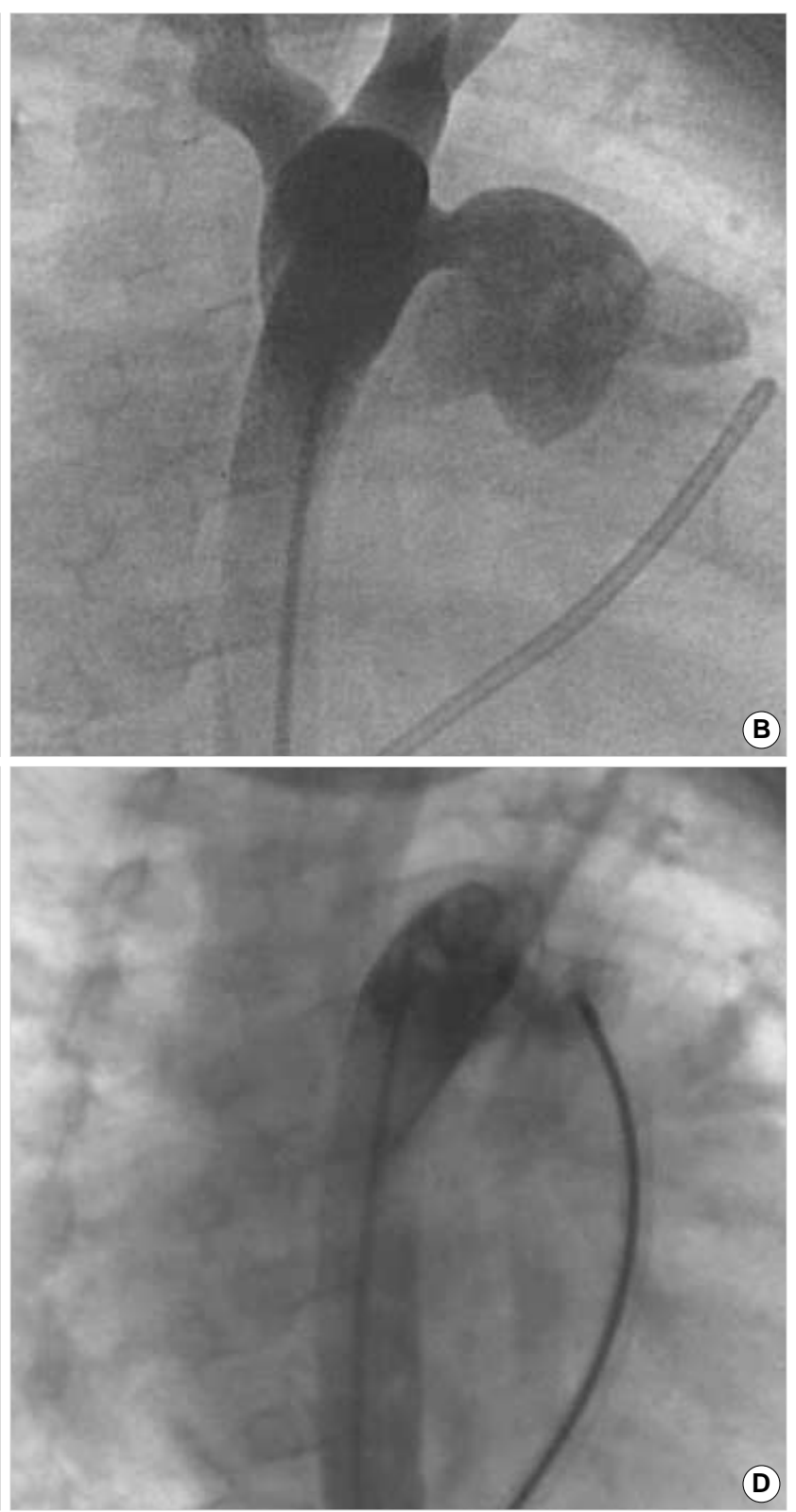

Fig. 3. Aortogram in lateral (A) and right anterior oblique view (B) displaying a large patent ductus arteriosus, 5 mm in diameter. Aortograms in lateral (C) and right anterior oblique view (D) after implantation of a 10/8 $\mathrm{mm}$ Amplatzer ductal oceluder show the protrusion of the retention disc into the aortic lumen. 
was observed on the origin of the left pulmonary artery, resulting in abnormal flow at a peak velocity of $2-2.5 \mathrm{~m} / \mathrm{sec}$. In one of these patients, we observed a partial obstruction of the left pulmonary artery. This was a 7-month-old patient (No 5 in Table 2) with a $5 \mathrm{~mm}$ duct, with a systolic pulmonary artery pressure of $79 \mathrm{mmHg}$, and the PDA of this patient was closed using a 10/8 mm ADO. After the deployment of the ADO, the device was observed to protrude into the descending aorta, thereby resulting in a mild narrowing of the descending aorta with no significant pressure gradient in the catheterization laboratory. After the procedure, on the echocardiogram, device encroachment was observed on the origin of the left pulmonary artery, resulting in a peak velocity of $2.5 \mathrm{~m} / \mathrm{sec}$. In the lung perfusion scan, a diffusely decreased perfusion of the left

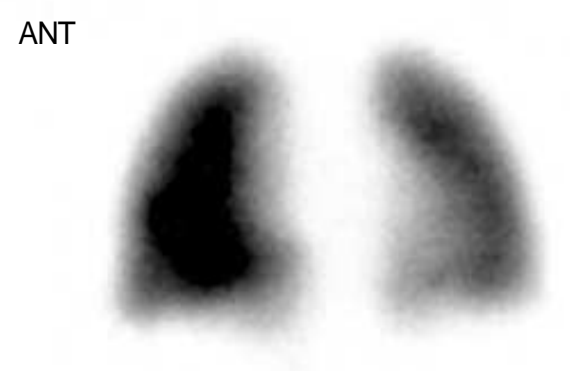

Fig. 4. A quantitative lung perfusion scan after deployment of a 10/8 $\mathrm{mm}$ ADO shows a decreased perfusion of the left lung. ANT, anterior
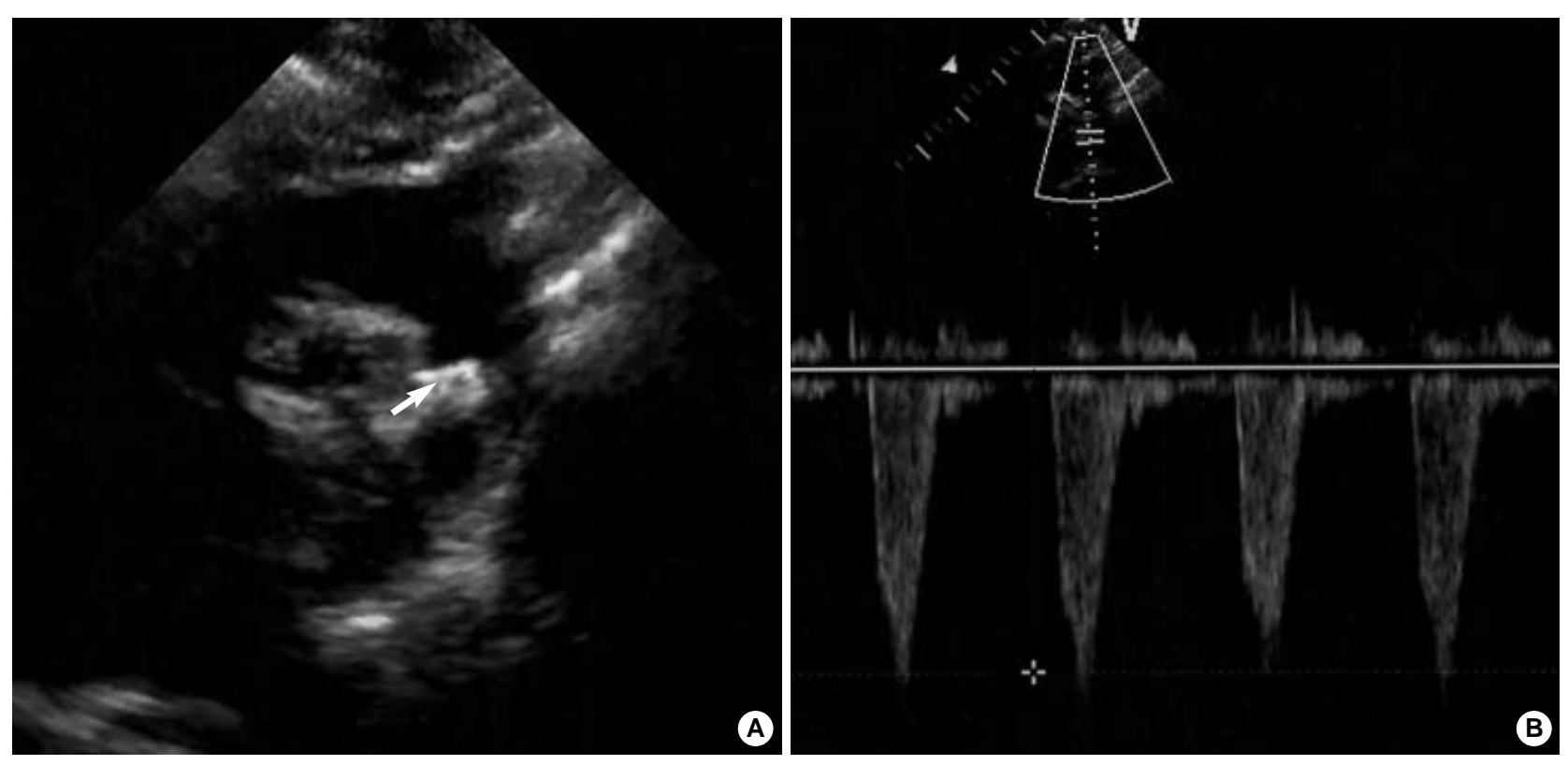

Fig. 5. (A) Transthoracic echocardiography shows the protrusion of the device (arrow) into the aortic lumen. (B) Doppler echocardiography in descending aorta shows a peak velocity of $1.6 \mathrm{~m} / \mathrm{sec}$. lung was observed, with a quantitative lung perfusion scan evidencing a 39\% flow to the left lung (Fig. 4). However, after the procedure, heart failure symptoms improved and the patient was discharged 2 days later. On the echocardiogram at 12 months after transcatheter closure of PDA, narrowing of descending aorta and left pulmonary artery was re-evaluated. Although the device was seen to protrude into descending aorta and left pulmonary artery, the peak velocity by Doppler echocardiography in descending aorta decreased from $2.2 \mathrm{~m} / \mathrm{sec}$ to $1.6 \mathrm{~m} / \mathrm{sec}$ (Fig. 5), and the peak velocity in left pulmonary artery decreased from $2.5 \mathrm{~m} / \mathrm{sec}$ to 1.7 $\mathrm{m} / \mathrm{sec}$. In the other 3 patients, although device encroachment was also observed on the origin of the left pulmonary artery, no significant obstructions were noted to exist. On followup Dopper echocardiography, there was no significant pressure gradient in left pulmonary artery in these patients.

\section{DISCUSSION}

Interventional PDA occlusion is an established and effective procedure, and a variety of devices have been introduced into clinical practice (10-14). Masura et al. (15) described the use of the ADO in the occlusion of moderate to large PDA. Thereafter, numerous clinical experiences with the transcatheter closure of moderate to large PDAs have been reported $(8,13,15)$. Although the results of interventional occlusion have been generally satisfactory, some complications have been reported to occur after transcatheter PDA closure procedures. According to the report of Faella and Hijazi (7), 15 (4.7\%) of 316 patients experienced complications, including one each patient with sudden death after procedure, hemolysis, 
transient asystole, ST depression due to blood loss, surgical closure due to device embolization, malpositioning of the device, and blood transfusion due to blood loss, and 8 patients with other, minor complications.

In our study, 4 major complications $(3.4 \%)$ and 6 minor complications (5.1\%) were encountered among 117 patients with PDA, with a minimum diameter of more than $3 \mathrm{~mm}$. In 2 patients, significant hemolysis was noted after transcatheter PDA closure, as a result of significant residual shunt. In previous reports, several investigators have reported hemolysis, device embolization, infection, and significant narrowing of the left pulmonary artery or the descending aorta as major complications $(8,13,16)$. Significant hemolysis after device deployment is primarily related to residual shunts, and occurs only rarely. This is believed to result from mechanical injury to the red blood cells, and the severe hemolysis appeared to have been associated with renal failure and coagulopathy. The reported rate of hemolysis varies, between $0 \%$ to $3.5 \%(13,17)$. The usual management of hemolysis involves the closure of the residual shunt, either surgically or via the deployment of the appropriate device. In our series of procedures, significant hemolysis was noted in 2 patients. In one of these patients, re-intervention was required, and residual shunts were eliminated after the deployment of the second device. In the other patient, hemolysis remained uncontrolled after re-intervention, and thus the patient was treated surgically.

Device embolization sometimes occurs, necessitating percutaneous retrieval or surgical removal. Device embolization has been identified as one of the most significant complications of interventional PDA occlusion (18-20). The reported embolization rate varies, between $0 \%$ to $16 \%(6,10,19)$. In an effort to decrease the embolization rate and determine the optimal position, it is necessary to reposition and redeploy the device. As noted earlier, one device embolization was observed among the present study group. This device was embolized into the left pulmonary artery, and percutaneously retrieved. At that time, other devices, such as the $\mathrm{ADO}$, were not available, and the patient was thus surgically managed.

Transcatheter occlusion of large PDA using ADO has been proved highly efficacious in large series $(5,13)$. Therefore, our treatment option of choice for large PDA occlusion involves the ADO. However, the implantation of the ADO is quite problematic in infants weighing less than $5 \mathrm{~kg}$ (21). From the perspective of large PDA closure in infants using ADO, the biggest concern regarding morbidity in relation to this device would be significant obstruction of the descending aorta and left pulmonary artery. Although the ADO may feasibly be deployed in infants with large PDA, the retention skirt may, in some cases, induce a narrowing of the aorta. Therefore, the aortic pressure gradient should be constantly monitored in the catheterization laboratory. In cases in which the ADO encroaches on the aortic lumen with a significant pressure gradient, it is recommended that the device be removed. In this study, after the deployment of the ADO, mild aortic narrowing without significant pressure gradient was observed in two of the patients. Both patients were infants of less than $7 \mathrm{~kg}$. On follow-up echocardiography at 12 months, the peak velocity in descending aorta decreased, as noted earlier. So, we speculate that this type of narrowing of aorta is expected to disappear gradually with subsequent growth of the child. The encroachment of the device on the origin of the left pulmonary artery was observed in four patients. However, in none of the patients the peak flow velocity of $>2.5$ $\mathrm{m} / \mathrm{sec}$ was observed by Doppler echocardiography. Although the encroachment of the device on the origin of the left pulmonary artery is of little concern with regard to the redistribution of blood flow, and is expected to lose its significance with subsequent somatic growth, careful follow-up with echocardiogram is necessary, especially in infants. In order to avoid complications such as aortic narrowing in infants with large PDA, the subsequent development of a modified $\mathrm{ADO}$ retention disk will also be necessary $(22,23)$.

Infective endocarditis after the implantation of the device is a rare complication. We could not find any reports regarding infective endocarditis after transcatheter PDA closure. In our series, one patient developed a high-grade fever for approximately 30 days after ADO implantation. We were unable to reveal the cause of fever in that patient, with the exception of infective endocarditis. After the device had been surgically removed, and the PDA ligation had been completed, the patient eventually achieved a full recovery. In this patient, another possibility as a cause of fever would be the nickel hypersensitivity to the ADO. Some authors reported nickel hypersensitivity after implantation of a nitinol-containing device $(24,25)$. According to their reports (24), high-grade fever and edema persisted after deployment of the PFO occluder (PFO star; Cardia, Burnsville, MN, U.S.A.). The patient's symptoms had persisted until the device was explanted surgically. In our patient, we did not consider nickel hypersensitivity as a cause of fever at that time. So, we did not carry out the test for possible nickel hypersensitivity. Although the risk of a significant hypersensitivity reaction to the nickel compound in ADO is small, nickel hypersensitivity should be considered before implantation of these devices.

In conclusion, percutaneous closure of PDA can be conducted successfully in the majority of patients, including symptomatic infants. This constitutes an alternative option prior to surgical treatment. However, some complications, including significant hemolysis, device embolization, important left pulmonary artery stenosis, iatrogenic coarctation, infective endocarditis, and nickel hypersensitivity may be observed in some cases. In order to minimize these complications, it is vitally important to select the appropriate device, depending on the ductal morphology and narrowest diameter, the size of the descending aorta, and the age and weight of the patient. Careful clinical evaluations and longer follow-up are 
also necessary. Further research into the next generation of such devices will be required in order to develop a more reliable and less problematic approach to the transcatheter closure of a large PDA in small infants.

\section{REFERENCES}

1. Portsmann W, Wierny L, Warnke H, Gerstberger G, Romaniuk PA. Catheter closure of patent ductus arteriosus: 62 cases treated without thoracotomy. Radiol Clin North Am 1971; 9: 203-18.

2. Uzun O, Hancock S, Parsons JM, Dickinson DF, Gibbs JL. Transcatheter occlusion of the arterial duct with Cook detachable coils: early experience. Heart 1996; 76: 269-73.

3. Tometzki AJ, Arnold R, Peart I, Sreeram N, Abdulhamed JM, Godman MJ, Patel RG, Kitchiner DJ, Bu'Lock FA, Walsh KP. Transcatheter occlusion of the patent ductus arteriosus with Cook detachable coils. Heart 1996; 76: 531-5.

4. Celiker A, Quershi SA, Bilgic A, Carminati M, Kirk S, Rosenthal E, Alehan D, Giusti S, Baker EJ, Tynan M. Transcatheter closure of patent arterial ducts using controlled release coils. Eur Heart J 1997; 18: 450-4.

5. Pass RH, Hijazi Z, Hsu DT, Lewis V, Hellenbrand WE. Multicenter USA Amplatzer patent ductus arteriosus occlusion device trial: initial and one-year results. J Am Coll Cardiol 2004; 44: 513-9.

6. Thanopoulos BD, Hakim FA, Hiari A, Goussous Y, Basta E, Zarayelyan AA, Tsaousis GS. Further experience with transcatheter closure of the patent ductus arteriosus using the Amplatzer duct occluder. $J$ Am Coll Cardiol 2000; 35: 1016-21.

7. Faella HJ, Hijazi ZM. Closure of the patent ductus arteriosus with the amplatzer PDA device: immediate results of the international clinical trial. Catheter Cardiovasc Interv 2000; 51: 50-4.

8. Al-Ata J, Arfi AM, Hussain A, Kouatli AA, Jalal MO. The efficacy and safety of the Amplatzer ductal occluder in young children and infants. Cardiol Young 2005; 15: 279-85.

9. Krichenko A, Benson LN, Burrows P, Moes CA, McLaughlin P, Freedom RM. Angiographic classification of the isolated, persistently patent ductus arteriosus and implications for percutaneous catheter occlusion. Am J Cardiol 1989; 63: 877-80.

10. Rashkind WJ, Mullins CE, Hellenbrand WE, Tait MA. Nonsurgical closure of patent ductus arteriosus: clinical application of the Rashkind PDA Occluder System. Circulation 1987; 75: 583-92.

11. Rao PS, Sideris EB, Haddad J, Rey C, Hausdorf G, Wilson AD, Smith PA, Chopra PS. Transcatheter occlusion of patent ductus arteriosus with adjustable buttoned device. Initial clinical experience. Circulation 1993; 88: 1119-26.
12. Moore JW, George L, Kirkpatrick SE, Mathewson JW, Spicer RL, Uzark K, Rothman A, Cambier PA, Slack MC, Kirby WC. Percutaneous closure of the small patent ductus arteriosus using occluding spring coils. J Am Coll Cardiol 1994; 23: 759-65.

13. Bilkis AA, Alwi M, Hasri S, Haifa AL, Geetha K, Rehman MA, Hasanah I. The Amplatzer duct occluder: experience in 209 patients. J Am Coll Cardiol 2001; 37: 258-61.

14. Kim Y, Chio JY, Lee JK, Sul JH, Lee SK, Park YH, Cho BK. Midterm result of the transcatheter occlusion of patent ductus arteriosus with duct-occlud device and procedure-related problems. Korean $J$ Pediatr 2004; 47: 36-43.

15. Masura J, Walsh KP, Thanopoulous B, Chan C, Bass J, Goussous Y, Gavora P, Hijazi ZM. Catheter closure of moderate- to large-sized patent ductus arteriosus using the new Amplatzer duct occluder: immediate and short-term results. J Am Coll Cardiol 1998; 31: 878-82.

16. Ali Khan MA, al Yousef S, Mullins CE, Sawyer W. Experience with 205 procedures of transcatheter closure of ductus arteriosus in 182 patients, with special reference to residual shunts and long-term follow-up. J Thorac Cardiovasc Surg 1992; 104: 1721-7.

17. Uzun O, Veldtman GR, Dickinson DF, Parsons JM, Blackburn ME, Gibbs JL. Haemolysis following implantation of duct occlusion coils. Heart 1999; 81: 160-1.

18. Verin VE, Saveliev SV, Kolody SM, Prokubovski VI. Results of transcatheter closure of the patent ductus arteriosus with the Botallooccluder. J Am Coll Cardiol 1993; 22: 1509-14.

19. Hijazi ZM, Geggel RL. Transcatheter closure of large patent ductus arteriosus (>4 mm) with multiple Gianturco coils: immediate and mid-term results. Heart 1996; 76: 536-40.

20. Galal O, de Moor M, Fadley F, Quershi S, Naffa S, Oufi S, Suhl M, Abbag F, Schmaltz AA. Problems encountered during introduction of Gianturco coils for transcatheter occlusion of the patent arterial duct. Eur Heart J 1997; 18: 625-30.

21. Hijazi ZM. Catheter closure of ductus arteriosus in adolescents and adults: what to use? Catheter Cardiovasc Interv 2002; 55: 519-20.

22. Vijayalakshmi IB, Chitra N, Rajasri R, Prabhudeva AN. Amplatzer angled duct occluder for closure of patent ductus arteriosus larger than the aorta in an infant. Pediatr Cardiol 2005; 26: 480-3.

23. Ewert P, Kretschmar O, Nuernberg JH, Nagdyman N, Lange PE. First closure of a large patent ductus arteriosus in an infant with an angulated nitinol plug. Catheter Cardiovasc Interv 2002; 57: 88-91.

24. Fukahara K, Minami K, Reiss N, Fassbender D, Koerfer R. Systemic allergic reaction to the percutaneous patent foramen ovale occluder. J Thorac Cardiovasc Surg 2003; 125: 213-4.

25. Lai DW, Saver JL, Araujo JA, Reidl M, Tobis J. Pericarditis associated with nickel hypersensitivity to the Amplatzer occluder device: a case report. Catheter Cardiovasc Interv 2005; 66: 424-6. 